\title{
O MINISTÉRIO PÚBLICO E SEUS MECANISMOS DE ACCOUNTABILITY: UMA ANÁLISE INSTITUCIONAL A PARTIR DA TESE DA "REVOLUÇÃO JUDICIARISTA"
}

\author{
Mateus Baptista de Siqueira \\ Eduardo Maines Breckenfeld
}

\begin{abstract}
Resumo
O presente artigo busca identificar como o desenho institucional do Ministério Público Brasileiro, especialmente no que se refere a falta de mecanismos suficientes de accountability para com seus promotores, se demonstrou como um fator decisivo para o desenvolvimento do ativismo judiciário de membros do Ministério Público frente às operações recentes de combate à corrupção, e as arbitrariedades decorrentes de tal fenômeno, especialmente em relação à operação Lava-Jato. Pretende-se demonstrar a hipótese de que o desencadeamento do fato descrito, compreendido como um fenômeno doutrinário-ideológico com o objetivo de legitimar a judicialização da política, a atuação política dos operadores jurídicos e o ativismo judicial (sintetizado teoricamente por Christian Lynch como a "Revolução Judiciarista"), teve como uma de suas principais causas a baixa accountability do MP. Trata-se de uma pesquisa explicativa de método descritivo, através da revisão bibliográfica direta. A interpretação dos mecanismos de accountability do MP se baseia em pressupostos teóricos do neo-institucionalismo. Foram utilizados dados e realizadas pesquisas acerca dos processos disciplinares do Conselho Nacional do Ministério Público e da legislação reguladora da instituição, além de bibliografia referente ao tema. Pôde-se concluir através do material analisado que o Ministério Público sofre de uma carência de instrumentos adequados de accountability externa e interna. A partir dessa conclusão, foi possível demonstrar como essa falta de accountability foi importante para o desenvolvimento da "Revolução Judiciarista" por um raciocínio hipotético-dedutivo.
\end{abstract}

Palavras-Chave: Ministério Público. Accountability. Instituições. Ativismo Judicial. Judiciarismo.

\begin{abstract}
This article aims to identify how the institutional design of the Brazilian Public Ministry, especially in regards to the lack of sufficient accountability mechanisms towards its prosecutors, has been demonstrated to be a decisive factor for the recent development of judicial activism from agents of the Public Ministry at the forefront of recent anti-corruption investigations, and the arbitrariness resulting from this phenomenon, specifically regarding the "Operation Car-wash". It is intended to demonstrate the hypothesis that the described fact, understood as a doctrinal-ideological phenomenon with the objective of legitimizing the judicialization of politics, the policial action of legal operators and of judicial activism (theoretically synthesized by Christian Lynch as a "Judicialist Revolution") had as one of its primary causes the low accountability of the Public Ministry. This research is characterized as an explanatory one of descriptive method, through bibliographic review. The interpretation of the concept of accountability and its mechanisms is based on the theoretical assumptions of neo-institutionalism. Through data and research about disciplinary proceedings of the National Council of the Public Ministry and of the legislation that regulates the institution, as well as the available literature on the subject. It was possible to conclude through the analysis of the data and of the literature that the Brazilian Public Ministry suffers from a lack of adequate accountability mechanisms, both externally and internally. From this conclusion, we were able to demonstrate through a hypothetical-deductive reasoning how this lack of accountability was important for the development of the "Judiciary Revolution".
\end{abstract}

Keywords: Public Ministry. Accountability. Institutions. Judicial Activism. Judicialism.

${ }^{1}$ Graduando em Direito pelo Setor de Ciências Jurídicas da Universidade Federal do Paraná (UFPR) e PesquisadorVoluntário do Programa de Educação Tutorial (PET-Direito) da UFPR, mateussiq1106@ gmail.com e ORCID iD: <https://orcid.org/0000-0002-0950-0162>.

${ }^{2}$ Graduando em Direito pelo Setor de Ciências Jurídicas da Universidade Federal do Paraná (UFPR) e PesquisadorBolsista do Programa de Educação Tutorial (PET-Direito) da UFPR, dumaines01@ @mail.com e ORCID iD: <https://orcid.org/0000-0002-4415-5149>. 


\section{Resumen}

Este artículo busca identificar cómo el diseño institucional del Ministerio Público Brasileño, especialmente por lo que se refiere a la falta de mecanismos suficientes de accountability para con sus agentes, se demostró como un factor decisivo para el desarrollo del activismo judicial de los miembros del Ministerio Publico frente a las recientes operaciones contra la corrupción, y las arbitrariedades derivadas de ese fenómeno, nomeadamente en relación con la "Operación lavado de autos". Se pretende demostrar la hipótesis de que la emergencia del hecho descrito, comprendido como un fenómeno doctrinal-ideológico con el objetivo de legitimar la judicialización de la política, la acción política de los operadores del derecho y el activismo judicial (resumido teóricamente por Christian Lynch como la "Revolución Judicialista") tuvo como una de sus principales causas la baja accountability del Ministerio Publico. Se trata de una investigación explicativa con método descriptivo, mediante revisión bibliográfica directa. La interpretación de los mecanismos de rendición de cuentas del MP se basa en los presupuestos teóricos del neoinstitucionalismo. Se utilizaron datos y se investigó sobre procesos disciplinarios del Consejo Nacional del Ministerio Público y la legislación reguladora de la institución, además de bibliografía sobre el tema. Se pudo concluir a través del material analizado que el Ministerio Público adolece de falta de instrumentos adecuados de accountability externa e interna. A partir de esta conclusión, fue posible demostrar cómo esta falta de accountability fue importante para el desarrollo de la "Revolución Judiciarista" por razonamiento hipotético-deductivo.

Palabras clave: Ministerio Publico. Accountability. Instituciones. Activismo Judicial. Judicialismo.

\section{INTRODUÇÃO}

O advento do estado de bem-estar social democrático de direito passou a obrigar o Poder Judiciário e o Ministério Público a garantir não mais apenas a liberdade negativa, no sentido de não impedimento, mas também a liberdade positiva, a igualdade de acesso à cidadania. Para Tércio Sampaio Ferraz Júnior (1994, p.18), isso alterou profundamente a divisão dos poderes das repúblicas. O Poder Judiciário e os promotores, agora, também poderiam decidir sobre questões antes exclusivamente discricionárias ao Poder Legislativo.

O fim do chamado "Estado liberal" no pós-guerra abriu espaço para a formação do Estado social, democrático e de direito, intervencionista e com uma Constituição dirigente, que traduziria uma ordem objetiva de valores ou compromissos constitucionais e representaria objetivos coletivos a serem realizados pelos governantes e pelos poderes constituídos. Essa constituição dirigente, conforme J. J. Gomes Canotilho:

[...] assenta no alargamento da função de direção, coordenação e planificação estadual (compreensão aceite numa teoria do Estado e da sociedade, socialista ou social democrática, mas combatida firmemente por uma teoria social individualista que vê nela o estreitamento da espontaneidade da ordem social e a desfiguração da Constituição da Liberdade). Uma constituição dirigente, como se viu a propósito do direito a prestações e se salientou agora a propósito do princípio da igualdade de oportunidades, pressupõe que o Estado por ela conformado não seja um Estado mínimo, garantidor de uma ordem assente nos direitos individuais e no título de propriedade, mas um Estado social, criador de bens colectivos e fornecedor de prestações. (CANOTILHO, 1994, p. 391) 
SIQUEIRA, M. B.; BRECKENFELD, E. M. O Ministério Público e seus mecanismos de accountability:

Uma análise institucional a partir da tese da "revolução judiciarista".

DOI: http:/ / dx.doi.org/10.5380/recp.v11i2.81591

Nesse sentido, houve uma politização do papel do Judiciário e do Ministério Público por sua nova função na defesa desses valores constitucionais, que muitas vezes resultam em conflitos jurisdicionais com os poderes Legislativo e Executivo. Os agentes institucionais, agora, teriam o dever de não apenas interpretar a Constituição, mas também de torná-la efetiva. No Brasil, esse processo se consolidou com a Constituição Cidadã.

Compreende-se que: atribuir poderes, discricionariedade e autonomia de atuação para os integrantes do parquet $^{3}$ é fundamental para uma atuação independente e efetiva. No entanto, essa autonomia deve ser acompanhada de instrumentos adequados de controle democrático pela sociedade civil, visando impedir avanços corporativistas, irregulares ou autoritários por parte dos promotores.

No caso brasileiro, presenciamos uma situação em que o Ministério Público goza de considerável prestígio e importância no cenário político. As recém deflagradas operações contra a corrupção e o crime organizado, como a Operação Lava-Jato, colocam promotores da Força Tarefa no centro da atenção da mídia e dos atores políticos.

A influência do fator político sobre a atuação do Ministério Público se manifesta em práticas que extrapolam as atribuições legais do parquet e em uma politização das fundamentações dadas pelos promotores por suas ações ou omissões, e de maneiras mais diretas, como pela proposição de projetos de lei $i^{4}$ atividade reservada, em tese, aos atores políticos propriamente ditos, vereadores, deputados e senadores).

Evidentemente, atitudes desviantes do ponto de vista normativo por parte de membros de certo órgão público são comuns e esperadas. No entanto, cria-se um problema quando não há instrumentos adequados de accountability para essas ações, criando incentivos para a manutenção de comportamentos irregulares.

Baseado nesse cenário, buscamos demonstrar que o alargamento da presença do Ministério Público no desenho institucional brasileiro tem como fundamento certos aspectos centrais e originários deste órgão, como: I - O desenho institucional do Ministério Público pela Constituição de 1988, que garante elevada autonomia e discricionariedade aos promotores e aos procuradores federais; II - O Ministério Público não é dotado instrumentos adequados de accountability.

Dessa forma, a "Revolução Judiciarista" pode ser um conceito-chave para compreender esse processo marcado pelo espectro da redemocratização constituinte, a primazia do interesse público

\footnotetext{
${ }^{3}$ Designa o corpo de membros do Ministério Público perante a jurisdição, pode ser um sinônimo de MP .

4 Caso notório de tal tentativa foi a campanha pelas "10 Medidas Contra a Corrupção", proposta legislativa do Ministério Público Federal. Disponível em: < http://www.mppr.mp.br/pagina-6193.html>
} 
SIQUEIRA, M. B.; BRECKENFELD, E. M. O Ministério Público e seus mecanismos de accountability:

Uma análise institucional a partir da tese da "revolução judiciarista".

DOI: http://dx.doi.org/10.5380/recp.v11i2.81591

na administração e a disfuncional autonomia do Ministério Público conjugada à inflação de suas competências. Como o objeto estudado é fundamentalmente o Ministério Público, trataremos tanto promotores como procuradores conjuntamente.

\section{MINISTÉRIO PÚBLICO: AUTONOMIA SEM ACCOUNTABILITY}

A promulgação constitucional trouxe uma série de inovações institucionais e programáticas para a atuação e o formato do Ministério Público. Anteriormente, os promotores eram organicamente parte do quadro de pessoal do Poder Executivo. Os procuradores-gerais eram nomeados pelos governadores de seu respectivo estado e poderiam ser demitidos ad nutum, isto é, não detinham mandato garantido. Não mais ligado ao Poder Executivo, o órgão passou a gozar de autonomia em relação aos três poderes e de uma maior discricionariedade de seus agentes. Com a nova Constituição, o órgão passa a ter uma nova função: a defesa dos interesses difusos da sociedade, garantindo que os direitos fundamentais estabelecidos pela constituição sejam concebidos pelos poderes da República.

O papel e a institucionalidade constitucional do Ministério Público se fazem no Título IV Da organização dos poderes - da Carta Magna Brasileira: "Instituição permanente, essencial à função jurisdicional do estado, incumbindo-lhes a defesa da ordem jurídica, do regime democrático e dos interesses sociais e individuais indisponíveis." (BRASIL, 1988) Percebe-se a sua separação dos demais poderes do Estado, não sendo mais subordinado ao Poder Executivo.

Conforme sintetizado por Gregório Assagra de Almeida:

Assim, entendemos que, das concepções sobre a natureza institucional do Ministério Público, a que melhor explica a sua postura institucional é a que o desloca da sociedade política, como órgão repressivo do Estado, para a sociedade civil, como legítimo e autêntico defensor da sociedade. Esse deslocamento se justificaria por três razões fundamentais. A primeira seria a social, que originou com a vocação do Ministério Público para a defesa da sociedade: ele assumiu paulatinamente um compromisso com a sociedade no transcorrer de sua evolução histórica. A segunda seria a política, que foi surgindo com a vocação da instituição para a defesa da democracia e das instituições democráticas. A terceira seria a jurídica, que se efetivou com a Constituição de 1988, que lhe concedeu autogestão administrativa, orçamentária e funcional e lhe conferiu várias atribuições para a defesa dos interesses primaciais da sociedade. Em verdade, o deslocamento do Ministério Público da sociedade. (ALMEIDA, 2008, p. 27)

Como descrito pelo ex-ministro da justiça, Eugênio Aragão, o fortalecimento do Ministério Público pelo constituinte foi "uma estratégia de desenho institucional que tinha como finalidade criar um contrapeso crítico e atuante ao conservadorismo originário do poder judiciário, muito resistente a qualquer tipo de reforma”. (ARAGÃO, 2017, p. 148) 
SIQUEIRA, M. B.; BRECKENFELD, E. M. O Ministério Público e seus mecanismos de accountability:

Uma análise institucional a partir da tese da "revolução judiciarista".

DOI: http://dx.doi.org/10.5380/recp.v11i2.81591

Esse novo papel do MP foi prescrito pelo legislador constituinte de maneira clara no artigo 129 da Constituição da República, que trata das funções institucionais do órgão. Lê-se em seu inciso II que umas das funções do parquet é "zelar pelo efetivo respeito dos Poderes Públicos e dos serviços de relevância pública aos direitos assegurados nessa Constituição, promovendo as medidas necessárias à sua garantia.” (BRASIL, 1988)

Historicamente, essa nova postura do Ministério Público pode ser compreendida como uma consequência da consolidação dos princípios do Estado de Direito no Brasil após a transição democrática. Evidentemente, um dos compromissos do Estado Democrático de Direito (no contexto de um estado de bem-estar social) é a busca por igualdade política e material.

Fábio Kerche (2007, p. 259) argumenta que, além da já descrita autonomia frente aos três poderes e de sua autonomia administrativa interna, o Ministério Público tem uma alta discricionariedade quanto a suas ações e iniciativas judiciais: o seu leque de atribuições é extenso, permitindo afirmar que há poucos assuntos referentes à sociedade brasileira que não possam ser transformados pela instituição em uma questão judicial a ser suscitada.

O pressuposto teórico por trás desse desenho institucional é o de que os burocratas de certo órgão público devem ter autonomia para decidir como as normas e as funções da instituição devem ser exercidas (PETERS, 2009, p. 8). O pressuposto normativo colocado nesse novo paradigma é de que a liberdade de atuação da burocracia se tornaria fator favorável à efetividade das políticas, permitindo aos servidores adaptarem suas ações às contingências específicas que encontram no momento de implementação das políticas públicas. (LOTTA; SANTIAGO, 2018, p. 21)

Marjorie Marona e Fábio Kerche (apud KERCHE; FERES, 2018, p.79) destacam o recente aumento na autonomia operacional do Ministério Público com a criação das forças-tarefa de combate ao crime organizado, efetivamente desprezando o princípio do promotor natural, autonomia esta incrementada por marcos legislativos como a lei de Organizações Criminosas (lei $\left.n^{\circ} 12.850 / 2013\right)$, que garantiu ao Ministério Público novos instrumentos legais como a delação premiada, aumentando consideravelmente a discricionariedade dos promotores em suas investigações. (KERCHE; MARONA, apud KERCHE; FERES, 2018, p. 90)

Esse desenho institucional permitiu que uma série de assuntos fossem passíveis de judicialização: quase toda questão jurídica que se relacione de alguma maneira com o que é estabelecido na Constituição pode tornar-se objeto de ação do Ministério Público. 


\subsection{A INTERPRETAÇÃO NEOINSTITUCIONALISTA}

A fim de melhor compreender a racionalidade por trás das ações transgressoras de determinados limites institucionais e legais pelos promotores, adotamos o referencial teórico do neoinstitucionalismo de escolha racional.

O neoinstitucionalismo abandonou o legalismo do institucionalismo antigo e incorporou dimensões de racionalidade e história para explicar como as instituições podem incentivar ou constranger determinados comportamentos (BATISTA; MARQUES, 2012, p. 8). Nesse sentido, elementos específicos das democracias aparecem como relevantes para entender o porquê de determinada atuação dos agentes em certa instituição; e os desenhos institucionais vêm sendo apontados como as principais respostas para os referidos atos desviantes das funções legal e formalmente estabelecidas pelo ordenamento legal passam a ser vistos como decisões cuidadosamente calculadas nos quais as partes envolvidas cuidadosamente maximizam utilidade, porém, com um custo para a sociedade.

Desse modo, a literatura institucionalista retomou a agenda da ciência política na década de 1980. O neoinstitucionalismo apresenta a preocupação em trazer as instituições de volta ao debate. Hall e Taylor (2003, p. 193), apresentam uma classificação dos neoinstitucionalismos em três variantes principais: o neoinstitucionalismo histórico, o neoinstitucionalismo sociológico e o neoinstitucionalismo da escolha racional.

Esse último neoinstitucionalismo se tornou predominante, e parte da ideia de que os indivíduos racionais agem de maneira a maximizar seus ganhos analisando os possíveis riscos e chances de sucesso de suas ações. O "homem econômico", da economia neoclássica (PERES, 2008, p. 65). Para o neoinstitucionalismo da escolha racional, trata-se de um sistema pensado, onde os agentes econômicos individuais analisam se há menos "riscos" e mais chance de "lucro" em suas ações.

A concepção do "homem econômico", ou a teoria da escolha racional, baseia-se na ideia utilitária de que os indivíduos atuam de maneira racional nos horizontes institucionais e econômicos em que estão inseridos com o fim de maximizar lucros e diminuir prejuízos. Evidentemente, tal interpretação não se limita apenas aos lucros estritamente econômicos. Gary S. Becker, um dos principais teóricos dessa corrente de análise do comportamento humano estende essa interpretação para fenômenos como a política, o crime e outros tipos de relacionamentos pessoais (BECKER, 1992, p. 38). Em síntese, descreve Jimena Hurtado Prieto: 
This framework assumes individuals are utility-maximizers and preferences are stable over time and similar among individuals. Individuals are then characterized by their utility functions and the arguments that constitute it. (PRIETO, 2005, p.9)

Paulo Sérgio Peres elucida que o neoinstitucionalismo se caracteriza em grande medida por teóricos que:

[...] julgam que as instituições são fatores de constrangimento/restrição às e de moldagem/estruturação das ações, pois limitariam seus cursos de ação possíveis e estabeleceriam uma escala de racionalidade entre estes. Com isso, ao longo do tempo, as instituições moldariam/estruturariam cada vez mais as preferências. (PERES, 2008, p. 64)

Atribui-se, dessa maneira, centralidade para as instituições como atores políticos que tomam suas decisões a partir de pressupostos e metodologias próprias, e não simplesmente delegadas pelo poder político soberano. (MARCH; OLSEN, 2008, p. 127)

Segundo North (1994, apud BATISTA; MARQUES, 2012, p. 17), as instituições importam, no sentido que estabelecem as "regras do jogo" e constrangem o comportamento dos atores.

Dessarte, compreende-se que os agentes públicos agem de maneira racional a partir de expectativas de lucro ou prejuízo, porém essa atuação ocorre dentro de determinado ambiente institucional que deve ser levado em conta.

Assim, por meio de uma análise dos mecanismos institucionais de controle e sancionamento às ações dos agentes do Ministério Público, podemos desenvolver uma compreensão mais precisa dos diferentes incentivos que levaram os procuradores e os promotores à sua nova postura mais ativa e interventora em diversas áreas da sociedade nos tempos recentes.

Portanto, apesar do Ministério Público ser uma instituição permanente de Estado, que tem como objetivo a representação dos interesses difusos da sociedade - devido à própria estrutura de qualquer burocracia -, os interesses dos agentes individuais podem diferir do restante da "sociedade civil". $\mathrm{Na}$ relação principal-agent (o principal sendo aquele que delega o poder, nesse caso, a Constituição Federal ou a sociedade brasileira como um poder constituinte originário e o agente como aquele a quem o poder é delegado), o agent detém expertise, ou seja, uma série de conhecimentos e meios de atuação específicos, podendo agir de acordo ou não, com os interesses do principal (BENDOR et al., 2001, p. 240). Isso se deve, entre outros fatores, à assimetria de informações entre o agent e o principal (MELO, 1996, p. 71). 


\subsection{ACCOUNTABILITY}

À essa delegação de poderes e autonomia, deveria haver igualmente a presença de instrumentos adequados de accountability. O conceito de accountability se refere aos mecanismos pelos quais os atores no sistema democrático (eleitos ou membros de uma determinada burocracia) devem prestar contas de seus atos perante um ator externo. Os principais tipos de accountability são de dois tipos: vertical e horizontal. A vertical é aquela exercida pelos eleitores nas eleições que, por meio do voto, escolhem se determinado político teve uma atuação positiva e deve ser reeleito ou atuou de maneira negativa e deve ser "punido" perdendo votos. Ou seja, há um incentivo para que os políticos, por serem accountable para com seus eleitores, orientarem sua atuação para que esteja em conformidade com os interesses desses. Já a accountability horizontal, é aquela exercida por agências e atores estatais em relação a outras agências e atores da estrutura do Estado. (PINHO, 2009, p. 1350). Nesse sentido, o Poder Judiciário é, de certa maneira, a instituição de accountability por excelência do regime democrático. (MELO, 1996, p. 28-9)

Johan P. Olsen sintetiza da seguinte maneira o significado do conceito para o poder público:

A accountability é importante porque muitos atores - eleitos e não eleitos - tomam decisões em nome de uma comunidade política, e porque existe a suspeita de que o poder provavelmente será mal utilizado. Portanto, o povo, como um corpo de cidadãos livres e autônomos, igual em participação política, consideração e valor, precisa responsabilizar os detentores do poder. (OLSEN, 2018, p. 66).

O autor considera ainda que: "Uma ordem política é um arranjo de instituições 'vivas' e uma instituição é um conjunto de regras e práticas comportamentais embutidas em estruturas de significados e recursos." (OLSEN, 2018, p. 70).

Alexandre de Moraes destaca que a "prestação de contas da administração pública, direta e indireta" se configura como princípio constitucional (MORAES, 2013, p. 285). Compreende-se, assim, a accountability do poder público como parâmetro fundamental do Estado brasileiro.

Ao conceito de accountability, se relaciona a ideia de responsiveness. Eduardo Martines Júnior, tratando sobre responsiveness no Ministério Público, considera que é um dever da autoridade pública atender às demandas e reclamações da sociedade de maneira rápida e efetiva. (MARTINES JÚNIOR, 2016, p. 30). O autor considera ainda que ambos os termos muitas vezes podem se confundir no debate sobre as instituições públicas pelo fato de que, na prática, a manutenção de um ambiente accountable e responsive passa por uma limitação da atuação da instituição (como o 
SIQUEIRA, M. B.; BRECKENFELD, E. M. O Ministério Público e seus mecanismos de accountability:

Uma análise institucional a partir da tese da "revolução judiciarista".

DOI: http://dx.doi.org/10.5380/recp.v11i2.81591

Ministério Público), dentro de um horizonte de atividade bem delimitado, a fim de impedir extrapolações na atuação de seus agentes (MARTINS JÚNIOR, 2016, p. 31).

Paradoxalmente, o fortalecimento do Ministério Público pela constituição de 1988, que teve como fim justamente a criação de uma espécie de órgão de accountability horizontal, fiscalizando políticos e burocratas (AVRITZER apud KERCHE; FERES, 2018, p. 37), acabou se tornando uma instituição sem instrumentos adequados de accountability para sua própria atuação.

Matthew Taylor e Timothy Power afirmam que o Ministério Público, por seu alto grau de autonomia e independência do restante da sociedade civil, age como um desestabilizador da "rede" de accountability entre as diferentes instituições públicas. Nas palavras dos autores:

Because these institutions are largely autonomous of their federal counterparts and respond to local political contexts, they introduce a wild card into the accountability process. (TAYLOR; POWER, 2011, p. 25)

De acordo com Rogério Arantes, os membros de certos órgãos públicos se encontram em uma situação na qual há grandes incentivos para que trabalhem em prol de seu próprio benefício e para que se reduza qualquer forma de accountability sobre suas próprias ações (ARANTES, 2019, p. 129). Assim, o autor considera que o próprio Estado:

[...] converte-se numa pluralidade de órgãos capazes de agir em função de seus próprios interesses. Por outro lado, e de modo complementar, os integrantes de tais órgãos podem ser vistos como atores em busca de rendimentos que só no âmbito do Estado é possível alcançar, sobretudo depois que conquistam autonomia orçamentária e administrativa para alocar, a seu bel interesse, com boa margem de discricionariedade e sem qualquer forma de accountability, os recursos financeiros junto aos seus. (ARANTES, 2019, p. 129)

A falta de accountability do Ministério Público se dá principalmente por uma falta de fiscalização externa da instituição por outros poderes. Alimentado pela noção de que o Ministério Público deve ter ampla autonomia para representar os interesses difusos da sociedade e que interferências de outros poderes sobre seus agentes seriam intrinsecamente danosas, há poucas maneiras pelas quais outros poderes e agências estatais podem sancionar irregularidades nas atuações dos promotores e procuradores federais. Tratando sobre o principal instrumento de accountability da corporação, esclarece Fábio Kerche:

A criação do Conselho Nacional do Ministério Público, em 2005, foi um avanço importante, mas com ressalvas. Uma delas é que a participação de atores externos à instituição ou ao mundo jurídico é minoritária. Isto é, a estrutura institucional do Ministério Público ainda é muito exposta aos interesses corporativos e às redes de dependência e relações pessoais de seus membros. (KERCHE, 2014, p. 120) 
SIQUEIRA, M. B.; BRECKENFELD, E. M. O Ministério Público e seus mecanismos de accountability:

Uma análise institucional a partir da tese da "revolução judiciarista".

DOI: http://dx.doi.org/10.5380/recp.v11i2.81591

Ou seja, há uma falta de fiscalização externa do MP, visto que a maior parte dos integrantes ${ }^{5}$

do Conselho Nacional do Ministério Público são promotores, com interesse em defender sua corporação. Portanto, além de um problema de transparência acerca do funcionamento das sanções externas do MP (MINISTÉRIO DA JUSTIÇA, 2013, p. 51), há um problema sério no desenho institucional do CNMP no que diz respeito à sua capacidade de punir devidamente os desvios dos promotores.

Ademais, acerca dos processos administrativos realizados pelo CNMP, a tendência é a de que:

[...] os procedimentos institucionais protejam fortemente os integrantes do Ministério Público, com vários recursos e prazos favoráveis ao acusado, e que os atores chave no processo sejam colegas de instituição do réu, como o corregedor, o presidente e a maior probabilidade de que o relator seja um dos conselheiros internos. (KERCHE, 2018, p. 19)

Vanessa Elias de Oliveira, Gabriela Lotta e Natália Pires de Vasconcelos salientam que o CNMP atua mais no sentido de ampliar e reafirmar a autonomia dos promotores do que exercer alguma forma de accountability interna. Para as autoras, através de uma análise de uma série de atos e normas recentes publicadas pelo conselho, percebe-se que há uma propensão de reforçar uma "autonomia sem accountability". Além disso, destacam que uma tendência que vem sendo apontada pela literatura recente é a preferência dos promotores por métodos extrajudiciais na resolução de conflitos, afastando, assim, mais um instrumento de accountability sobre suas ações: o próprio Poder Judiciário. (OLIVEIRA; LOTTA; VASCONCELOS, 2020, p. 193).

Ernani Carvalho e Natália Leitão destacam a baixa influência que os políticos e, portanto, os poderes eleitos da sociedade têm para interferir na atuação do Ministério Público no Brasil. Para os autores, autonomia e discricionariedade, em ambientes democráticos, devem ser acompanhados na mesma medida de accountability e controle social. O formato do Ministério Público brasileiro se apresenta como algo incomum em uma democracia (CARVALHO; LEITÃO, 2010, p. 414).

\section{REVOLUÇÃO JUDICIARISTA}

O papel assumido pelo Ministério Público, após a promulgação da Constituição de 1988, pode ser compreendido a partir da tese lançada por Christian Edward Cyril Lynch sobre a denominada "Revolução Judiciarista". No artigo em que ele concebe e determina o conceito, o

5 O CNMP possui 14 membros, sendo estes: o Procurador Geral da República (Presidente do órgão), quatro membros do MPU, 3 dos MP's estaduais, dois juízes indicados pelo STF e STJ, dois advogados indicados pela OAB e dois cidadãos de notável saber jurídico e reputação ilibada pelo Congresso Nacional. 
SIQUEIRA, M. B.; BRECKENFELD, E. M. O Ministério Público e seus mecanismos de accountability:

Uma análise institucional a partir da tese da "revolução judiciarista".

DOI: http://dx.doi.org/10.5380/recp.v11i2.81591

autor se refere a essa movimentação como aquela na qual - derivada da produção intelectual do neoconstitucionalismo de Luís Roberto Barroso, mas também voltada ao pensamento de Rui Barbosa na gênese republicana - as instituições judiciárias adquirem um papel de vanguarda civilizatória na modernização social brasileira a partir de sua apropriação pela jurisdição constitucional, agindo tal como um "poder moderador" (ressalvando o caráter semântico do termo, sem adentrar na discussão monárquica) responsável pelo equilíbrio institucional e avanço do país.

Essa atuação se adequaria aos moldes tenentistas da primeira metade do século XX e os novos "tenentes" não são mais os oficiais de baixa patente empunhando suas metralhadoras e baionetas contra aquela "podridão fétida da política", mas sim uma nova classe de magistrados e promotores que encarnam o espírito de um "Aufklärung" como mote de suas atribuições constitucionais. Esses “togados”, primam pela moralidade pública, honestidade geral e pela limpeza da política pelo drenar das mazelas da corrupção. Junto dessas teses, remontam-se análises da sociologia brasileira sobre a prevalência de um país em que se vive de maneira desonesta em todas as ordens e espaços de convivência. Dessa constatação, seriam eles os responsáveis pela revolução ética e iluminista, pois estão moralmente legitimados. Essa legitimação viria de alguns fatores, em suma três: a destinação meritocrática para assumir esse caráter visto que foram alçados a esses postos mediante um concurso público, a formação intelectual na condição de bacharéis qualificados para o exercício da razão pública e, como síntese, o fato de não serem políticos, logo dotados de puras intenções com o poder público. Em suma, o caráter é antipolítico, visto que a política no Brasil se confundiria com a atuação maculada da "velha política" de elites oligárquicas repetindo o pensamento militarista (tenentista) da Revolução de 1930.

A conjugação desses fatores atribui caracteres políticos claros ao Poder Judiciário e sua instituição mais jovem, o Ministério Público. Assim, recebe essa carga e, pela sua ampla liberdade institucional, assume o papel dos demais poderes institucionais e atua conjuntamente com as classes médias urbanas, magistrados e setores midiáticos como líderes de uma revolução civilizacional no geist da limpeza nacional. Esses fatores se relacionam diretamente com o lapso institucional na regulação, mediante o princípio liberal dos "checks and balances" das atribuições do Ministério Público no movimento constitucional que resultou na Constituição de 1988.

A partir disso, a conduta dos membros do Ministério Público e a expectativa social em torno deles repousa na necessidade de refletir a entidade qualitativa e abstraída da "voz das ruas", com o papel de legitimar a atuação, permitindo que o papel contramajoritário desse órgão jurisdicional em

\footnotetext{
"Aufklärung é atinente ao esclarecimento ou iluminação kantiana presente no seu opúsculo "O que é Esclarecimento". 
SIQUEIRA, M. B.; BRECKENFELD, E. M. O Ministério Público e seus mecanismos de accountability:

Uma análise institucional a partir da tese da "revolução judiciarista".

DOI: http:/ / dx.doi.org/10.5380/recp.v11i2.81591

um princípio político. Tal papel, ainda que ilegítimo e potencialmente corrosivo para o Estado

Democrático de Direito, não é passível de regulamentações exteriores.

Retomando a revolução teorizada por Lynch, há uma certa crença dentro dos setores sociais urbanos e da academia de que a "cultura bacharelesca" descrita por Sérgio Adorno Abreu como aquela que se via destinada a guiar a nação brasileira e habilitada para tal ofício desafiador, guie, de fato, o processo civilizacional brasileiro a partir da consolidação de um modelo liberal na organização de um "modelo singular de cidadania" (1988, p. 19). A partir da necessidade de se afirmar os direitos fundamentais e garantir efetividade para o texto constitucional, aqueles dotados de alguma legitimidade institucional, devem fazer o que for possível para esta tarefa. Disso decorre a defesa desse papel atuante. Na obra de Luís Roberto Barroso, há essa defesa que, para Lynch, é judiciarista. Por exemplo, ao citar a tomada de atribuições executivas, Barroso explica que o tradicional modelo que aparta de modo fronteiriço o Direito da Política deve ser racionalizado ou até mesmo relativizado quando se trata de questões que circundam os direitos fundamentais devendo tomar decisões "parcialmente [...] voluntaristas e arbitrárias" (BARROSO, 2012, p. 43).

Majoritariamente, Barroso está descrevendo o modo como o magistrado deve decidir de acordo com o novo marco constitucional, no entanto, essa tese transborda a atuação do magistrado e é um paradigma da tônica discursiva dentro da sociedade. O Ministério Público não é imune e, inclusive, possui a função constitucional de defender a ordem jurídica brasileira.

Nessa linha, Rogério Bastos Arantes defende que é pertinente tal politização da atuação jurisdicional do Estado e isso não seria por "culpa" dos procuradores, mas sim em virtude das atribuições institucionais que lhes foram de alguma maneira impostas. Portanto, a transferência da esfera resolutiva dos conflitos em torno da defesa de direitos fundamentais difusos e coletivos, além da ação penal pública, são deveres funcionais dos integrantes desse órgão. Daí, também decorrem as extensas garantias dessa atuação, alçadas legalmente ao pé da magistratura, visto que pendem responsabilidades inerentes dessa atuação, que não só devem proteger a adequada atuação desses profissionais como dissociá-los da política (ARANTES, 1999, p. 84).

A questão se torna problemática quando prerrogativas ameaçam ser rompidas ou quando a atuação de indivíduos representantes investidos em posições de responsabilidade institucional. Não só o Ministério Público possui a atribuição de custos legis (fiscal da lei), como também deve primar pelo interesse público na sua atuação conforme pontuado por Lenio Streck (2019). Assim, o tenentismo togado descrito não é legítimo, visto que parte da premissa de atuação em prol de ambições privadas ou corporativas que não devem ou deveriam dizer respeito ao leque de possibilidades já bem amplos garantidos a atuação jurisdicional do órgão essencialmente público. 
SIQUEIRA, M. B.; BRECKENFELD, E. M. O Ministério Público e seus mecanismos de accountability:

Uma análise institucional a partir da tese da "revolução judiciarista".

DOI: http:/ / dx.doi.org/10.5380/recp.v11i2.81591

Assim, a conduta judiciarista não só carece de previsão administrativa, bem como viola o pacto democrático e a separação de poderes. É contraditório que o órgão responsável por zelar e observar as movimentações internas decorrentes do regime jurídico democrático brasileiro assuma papéis que não são próprios ou tensione, mediante pressão política e movimentações com o mote da "voz da sociedade brasileira”. O equilíbrio institucional brasileiro mostra-se fragilizado por si só ao assentir ou legitimar condutas ímprobas que se dissociam do espírito público próprio do Artigo 37 da Constituição no campo da administração pública. A atuação, portanto, é voltada para a esfera particular do procurador ou à sua pretensão política de participação na esfera pública sendo depositário de um ofício público que não deveria privá-lo de tal, contaminando e gerando carência na isenção necessária para a prestação jurisdicional. Por exemplo, nesse panorama, ele pode omitirse de levar à justiça algo que pode conter relevância ou agir deliberadamente com intenções diferentes daquelas previstas nas suas atribuições funcionais.

Não só no exercício da função, a atuação judiciarista pode ser perceptível nas manifestações do procurador diante da imprensa ou por meio de redes sociais, fundações, institutos ou outras esferas da sociedade civil. A manifestação de opinião ou a convocação da sociedade para pressionar as decisões judiciais ou constranger os sujeitos que estão diante do Poder Judiciário 7 . Pode-se objetar que tal conduta não é sancionada, com a indicação de que a liberdade de expressão garante tais manifestações. No entanto, não há tal previsão e isto está categorizado no ordenamento jurídico. O MP também é regido pelos verbos legalidade, impessoalidade, moralidade, publicidade e eficiência; constantes no caput do Art. 37 da Constituição. Ademais, pela legislação infraconstitucional, especificamente, no artigo 43 da Lei 8.625/1993 (Lei Orgânica Nacional do Ministério Público) que vincula a atividade ministerial à ilibada conduta pública e particular (inciso I), zelo pelo prestígio da justiça (inciso II) e isenção na atuação jurisdicional (inciso VII). Previsões legais não cumprem papel de recomendação ou de mera moralidade extrajurídica, mas incidem na necessidade de adequar as condutas às normas que possuem claro efeito vinculante como regra de função e, na atuação jurisdicional, enquanto regra de tratamento.

Embora não seja objeto desse estudo, o ativismo judicial - que, para Gilmar Mendes e Georges Abboud, "trata-se da suspensão, pelo Poder Judiciário, dos pré-compromissos democráticos (...), que dão lugar, pura e simplesmente, à subjetividade de quem estiver julgando" (2019, p. 4) - é fruto da mesma movimentação do judiciarismo na atuação ministerial, a saber aquela que busca arregimentar e engendrar um processo civilizatório a partir do caminho

\footnotetext{
7 Em abril de 2018, o Procurador da República Deltan Dallagnol anunciou que faria um jejum pela denegação de um Habeas Corpus ao ex-presidente Lula. https://oglobo.globo.com/brasil/deltan-diz-que-fara-jejumdurantejulgamento-de-hc-de-lula-22548453
} 
SIQUEIRA, M. B.; BRECKENFELD, E. M. O Ministério Público e seus mecanismos de accountability:

Uma análise institucional a partir da tese da "revolução judiciarista".

DOI: http://dx.doi.org/10.5380/recp.v11i2.81591

jurisdicional. Esses fenômenos se retroalimentam no seu desenvolvimento a partir da constatação de que possuem as mesmas raízes teóricas no neoconstitucionalismo.

O judiciarismo e seus consequentes incidem sobre o baixo accountability do Ministério Público, elemento constitutivo deste órgão, tendo em vista a sua necessidade de independência para que possa fiscalizar a estrutura institucional brasileira. Contudo, com a inflação de atribuições e competências, ser pouco accountable é, potencialmente, gerador de descompassos e conflitos institucionais, que conjugados ao ativismo judicial, podem ser uma das raízes causais da crise institucional contemporânea por alterar substantivamente as competências, atribuições, prerrogativas e titularidades funcionais dos agentes. A progressiva extensão das competências, prerrogativas e poderes-deveres funcionais dos membros do Ministério Público própria da movimentação judiciarista, não são condizentes, a partir de uma análise neoinstitucional, com um baixo accountability interno e externo e com uma ampla liberdade, fluidez e intervenção sobre os poderes da república e suas instituições em escala multidimensional.

\section{CONSIDERAÇÕES FINAIS}

Diante dos problemas introduzidos, foi conceituada a gênese do atual modelo do Ministério Público a partir da redemocratização que se consolidou com o regime constitucional pós-88. Nesse sentido, o Ministério Público adquiriu amplas autonomias para atuar como protetor sistêmico da ordem jurídica constituída. Isso retoma e evidencia um novo design institucional, em que esse órgão ganhou um papel de fiscalização dos demais poderes. Para que essa fiscalização se desse adequadamente no âmbito de um Estado Democrático Constitucional de Direito, a autonomia necessária foi protegida com alguns preceitos constitucionais como a independência funcional, administrativa e orçamentária. Não só em torno das garantias institucionais em relação aos outros poderes, a legislação garantiu proteção ao agente promotor com a inamovibilidade e a independência do procurador frente à sua instituição. Isso possibilitou e garantiu a atuação do órgão em diversos cenários da nova institucionalidade democrática, levando uma série de conflitos e temas à ação jurisdicional, além da intervenção fiscalizadora em outros litígios de caráter privado, com a constitucionalização do direito privado.

O desenvolvimento desse órgão pode ser explicado a partir do neoinstitucionalismo da escolha racional em que a ação dos agentes se dariam a partir de uma visão econômica de perdas e ganhos sofridos por ele a partir de um constrangimento ou prêmio regulado, mensurado e 
SIQUEIRA, M. B.; BRECKENFELD, E. M. O Ministério Público e seus mecanismos de accountability:

Uma análise institucional a partir da tese da "revolução judiciarista".

DOI: http:/ /dx.doi.org/10.5380/recp.v11i2.81591

sancionado pela instituição, que desenharia esse paradigma possibilitando a atuação do Procurador conforme suas atribuições e deveres funcionais.

Paralelo aos condicionamentos que podem ser observados a partir do marco teórico do neoinstitucionalismo da escolha racional, haveria a necessidade um accountability que possibilitasse os cumprimentos das determinações desse principal agent. Isso não é apenas preceituado pela literatura, mas também o espírito constitucional da administração pública exige a transparência como um paradigma de gestão. O Ministério Público, portanto, é um órgão prima face que tem a função-dever de accountability no que concerne ao regime jurídico brasileiro. Aí reside uma contradição com o fato de que a instituição responsável por fiscalizar, não está sujeita a investigações na mesma intensidade, se tornando uma contradição interna aos seus pressupostos basilares mínimos.

Essa deficiência interna se mantém pelo razoável argumento de que a instituição fiscalizadora deve ser livre formal e materialmente. Com isso, o accountability do MP é feito pelo Conselho Nacional do Ministério Público, que, contudo, é uma instituição quase que totalmente corporativa e internalizada pelo Ministério Público, gozando de pouca autonomia material, o que prejudica o cumprimento dos princípios da administração pública pelo órgão.

Por consequência, o Ministério Público, com sua progressiva extensão e presença no ordenamento brasileiro, coexiste com seus mecanismos de accountability fragilizados. Esse descompasso, fragiliza as relações institucionais brasileiras, fugindo aos propósitos históricos envolvidos na sua recepção e reforma com a constituição de 1988. Em suma, falta de autonomia, transparência, accountability externo, instrumentos de controle e sua independência que cresce desproporcionalmente às suas competências; são potencialmente responsáveis pela distensão institucional observada no Brasil.

Ainda é incipiente buscar explicações complexas e definitivas sobre as razões e causas disso, contudo, a explicação desenvolvida por Lynch com a "Revolução Judiciarista" aparenta ser promissora na compreensão desse fenômeno pela pretensão civilizatória e política daqueles responsáveis pela defesa da ordem jurídica brasileira. 


\section{REFERÊNCIAS}

ADORNO, Sérgio. 1988. Os aprendizes do poder: o bacharelismo liberal na política brasileira. São Paulo: Paz e Terra.

ALMEIDA, G. A. 2008. O Ministério Público no Neoconstitucionalismo: Perfil Constitucional e Alguns Fatores de Ampliação de sua Legitimação Social. In: CHAVES, C.; ALVES, L. B. M.; ROSENVALD, N.. Temas atuais do Ministério Público. Rio de Janeiro: Lumen Juris, pp. 17-59.

ARAGÃO, E. 2017. Ministério Público. In.: Alves, G., NASSIF, M. I.; ROSÁRIO, M.; RAMOS, W. Enciclopédia do Golpe (Vol. 1). Bauru, SP: Editora Canal 6.

ARANTES, R. B.; MOREIRA, T. M. Q. 2019. Democracia, instituições de controle e justiça sob a ótica do pluralismo estatal. Opinião Pública, Campinas , v.25, n.1, pp. 97-135.

ARANTES, R. B. 1999. Direito e política: o Ministério Público e a defesa dos direitos coletivos. Revista Brasileira de Ciências Sociais. São Paulo, v. 14, n. 39, pp.83-102. Disponível em: [https://www.scielo.br/scielo.php? script $=$ sci arttext\&pid $=$ S010269091999000100005\&lng=en\&nrm=iso] . Acesso em: 08 de Maio de 2020.

ARAT, L. O. 2013. Corruption and democracy in Brazil: The struggle for accountability. Journal of Comparative Policy Analysis: Research and Practice, v.15 n.2, pp. 199-202. Disponível em [http://www.scielo.br/scielo.php? script $=$ sci arttext\&pid=S0104-

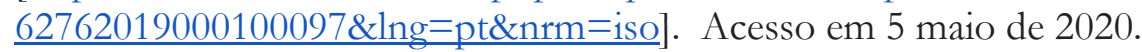

BARROSO, L. R. 2012. Constituição, Democracia e Supremacia Judicial: Direito e Política no Brasil Contemporâneo. RFD-Revista da Faculdade de Direito da UERJ. [S.l.], n. 21. pp. 5-43. ISSN: 2236-3475. Disponível em: [https://www.epublicacoes.uerj.br/index.php/rfduerj/article/view/1794]. Acesso em: 5 de maio de 2020.

BATISTA, M.; MARQUES, R. 2012. Instituições Políticas e Corrupção: uma análise da literatura comparada. Revista Politica Hoje, v. 21, n. 1. pp.7-42.

BECKER, G. S. 1992. The Economic Way of Looking at Life, Nobel Lectures, Economics.

BENDOR, J.; GLAZER, A.; HAMMOND, T. H. 2001. Theories of Delegation. Annual Review of Political Science 4, pp. 235-269.

BRASIL. [Constituição (1988)]. 2019. Constituição da República Federativa do Brasil: promulgada em 5 de outubro de 1988. 11. ed. Barueri: Manole.

BRASIL. Lei Orgânica do Ministério Público, de 12 de Fevereiro de 1993.

CANOTILHO, J. J. G. 1994. Constituição Dirigente e Vinculação do Legislador: contributo para a compreensão das normas constitucionais programáticas. Ed. Coimbra: Coimbra.

CARVAlHO, E.; LEITÃO, N. 2010. “O Novo Desenho Institucional do Ministério Público e o processo de Judicialização da Política”. Revista Direito GV,vol.6,no. 2, pp. 399-422.

FERRAZ JÚNIOR, T. S. 1994. O Judiciário frente a divisão dos poderes: um princípio em decadência? Revista USP, n. 21. pp.13-21. 
HALL, P. e TAYLOR, R. 2003. "As Três Versões do Neoinstitucionalismo”. Lua Nova: Revista de Cultura e Politica, no.58, pp. 193-224.

KERCHE, F. 2007. Autonomia e Discricionariedade do Ministério Público do Brasil. Dados Revista de Ciências Sociais, Rio de Janeiro, v. 50, n. 2, pp. 259-79.

KERCHE, F. 2018. Conselho Nacional do Ministério Público e Accountability. In.: $42^{\circ}$ Encontro Anual da Anpocs. Anais Eletrônicos. Caxumbu, MG. Disponível em:[http://www.anpocs.com/index.php/papers-40-encontro-3/gt-31/gt07-16]. Acesso em 20/03/2020.

KERCHE, F. 2014. O Ministério Público no Brasil: relevância, características e uma agenda para o futuro. Revista da USP, v. 101, pp. 114-120.

KERCHE, F.; FERES JÚNIOR, J. 2018. Operação Lava Jato e a Democracia Brasileira. São Paulo, Editora Contracorrente.

LOTTA, G.; SANTIAGO, A. 2018. Autonomia e discricionariedade: matizando conceitos-chave para o estudo da burocracia. Revista Brasileira de Informação Bibliográfica em Ciências Sociais, n. 83, pp. $21-42$.

LYNCH, C. E. C. 2017. Ascensão, fastígio e declínio na Revolução Judiciarista. Insight Inteligência, n. 79. p.158-168. Disponível em: [https://insightinteligencia.com.br/ascensao-fastigio-e-declinioda-revolucao-judiciarista/]. Acesso em: 29/04/2020.

MARCH, J. G.; OLSEN, J. P. 2008. Neo-institucionalismo: fatores organizacionais na vida política. Rev. Sociol. Polit., Curitiba, v. 16, n. 31, pp. 121-142.

MARTINES JÚNIOR, E. 2016. Accountability, responsiveness e Ministério Público. Caderno de Administração, v. 10, n. 1, pp. 1-39.

MELO, M.A. 1996. Governance e Reforma do Estado: o paradigma agente x principal. Revista do Serviço Público. Brasília, v. 120, nº 1. pp.67-82

MENDES, G. F.; ABBOUD, G. 2019. Ativismo judicial: notas introdutórias a uma polêmica contemporânea. Revista dos Tribunais, v. 108, n. 1008, pp. 43-54.

MINISTÉRIO DA JUSTIÇA. 2013. Desafios da Transparência no Sistema de Justiça Brasileiro. Brasília: Secretaria de Reforma do Judiciário.

MORAES, A. 2013. Direito constitucional. 29 ed. São Paulo: Atlas.

PERES, P. S. 2008. Comportamento ou instituições? A evolução histórica do neo-institucionalismo da ciência política. Revista Brasileira de Ciências Sociais, São Paulo, v. 23, n. 68, pp. 53- 71.

PETERS, G. 2009. Still the century of bureaucracy? The roles of public servants. Public Policy and Administration, Vinius, v. 1, n. 30, pp. 7-21.

PINHO, J. A. G.; SACRAMENTO, A. R. S. 2009. Accountability: já podemos traduzi-la para o português? Revista de Administração Pública, v. 43, n. 6, pp. 1343-1368. 
SIQUEIRA, M. B.; BRECKENFELD, E. M. O Ministério Público e seus mecanismos de accountability:

Uma análise institucional a partir da tese da "revolução judiciarista".

DOI: http://dx.doi.org/10.5380/recp.v11i2.81591

PRIETO, J. H. 2005. The Utilitarian Foundations of the Economics approach to Human Behavior. Documento CEDE. Colômbia, Universidad de los Andes, v.27. pp.1-31.

OLIVEIRA, V. E.; LOT'TA, G. S.; VASCONCELOS, N. P. 2020. Ministério Público, Autonomia Funcional e Discricionariedade: ampla atuação em políticas públicas, baixa accountability. Revista De Estudos Empiricos Em Direito, v.7, n.1, pp. 181-195.

OLSEN, J. P. 2018. Accountability democrática, ordem política e mudança: explorando processos de accountability em uma era de transformação europeia. Brasília: Enap.

STRECK, L. L. 2019. É possível que o Ministério Público seja imparcial? Revista Eletrônica Consultor Jurídico, São Paulo. Disponível em: [https://www.conjur.com.br/2019-mar-30/diario-classepossivel-ministerio-publico-seja-imparcial]. Acesso em: 06 de maio de 2020. 